\title{
Pharmaceutical Equivalence and Stability of Furosemide Tablets in Argentina
}

Marta I.V. Brevedan1 ${ }^{1}$, María A. Varillas ${ }^{1}$, and Noelia L. Gonzalez Vidal ${ }^{1,2^{*}}$

${ }^{1}$ Departamento de Biología, Bioquímica y Farmacia, Universidad Nacional del Sur, Bahia Blanca, Argentina.

${ }^{2}$ Consejo Nacional de Investigaciones Científicas y Técnicas (CONICET), Bahía Blanca, Argentina.

e-mail:nlgvidal@uns.edu.ar

\begin{abstract}
Furosemide is a widely used diuretic, indicated in the treatment of hypertension and edema. This active pharmaceutical ingredient is classified as Class IV in the Biopharmaceutical Classification System. The World Health Organization recommends an oral dose of $40 \mathrm{mg}$. The aim of the present work was to evaluate and compare critical quality attributes, including in vitro dissolution characteristics, of eight furosemide tablet brands from the Argentine market and determine their pharmaceutical equivalence. Furthermore, this research aimed to evaluate the effect of storage for 12 months (natural aging conditions) on those critical properties. At time zero of analysis, all evaluated samples fulfilled specifications for friability, hardness, disintegration, assay, uniformity of dosage units, and dissolution tests. After storage, all formulations fulfilled the assay and dissolution test specifications, with no statistical differences recorded for the obtained results. Comparison of dissolution profiles was also assessed in terms of the model-independent parameter called dissolution efficiency. Highly significant differences were recorded between reference and four multisource formulations. The same differences were found at the beginning of the study (time zero) and after 12 months of storage. The product with the lowest dissolution efficiency results was associated with highly significant differences when compared to the other formulations. However, the obtained results reveal that the evaluated samples complied with codified quality control tests, and consequently, can be qualified as pharmaceutical equivalents. Natural aging conditions did not affect the stability of the evaluated furosemide products.
\end{abstract}

KEYWORDS: Furosemide, pharmaceutical equivalence, stability, tablets, dissolution

\section{INTRODUCTION}

$\mathrm{P}$ harmaceutical equivalents consist of formulations with an identical active pharmaceutical ingredient (API), in the same molar amount and dosage form, which are intended to be used by the same route of administration. In addition, it is essential that the compared products fulfill quality control standards, i.e., identity, API content, uniformity of dosage units, dissolution performance, and information concerning storage (1, 2). Another critical biopharmaceutical parameter to be considered is the "dissolution stability", because it is critical that the dissolution behavior of a formulation remain unaffected throughout its storage and use period (3).

Furosemide (FURO), or 4-chloro-2-(2-furylmethylamino)5-sulfamoylbenzoic acid, is a loop diuretic, widely used by oral route for hypertension and edematous states treatment. This API presents an acidic nature, with a pKa value of 3.9, and an oral absorption mostly from gastric and upper small intestinal epithelium $(4,5)$.

In the Biopharmaceutics Classification System (BCS), FURO is labeled as Class IV (6-9). When this class of API is formulated as immediate-release solid dosage form, intended to be administered by the oral route, it is expected to be subjected to bioequivalence studies. In fact, local legislation indicates that pharmaceutical products containing FURO should undergo a bioavailability/bioequivalence (BA/BE) study (10). To the best of authors knowledge, there have been no studies about $\mathrm{BA} / \mathrm{BE}$ of marketed products reported in the literature.

However, it remains likely that in vitro studies can serve as a reliable indicator for potential problems with

*Corresponding author 
formulations containing Class IV APIs. Previous studies comparing different FURO products were reported in the literature (11-15). Particularly in Argentina, Maggio et al. have studied eight batches of FURO tablets of three different brands, Ruiz et al. evaluated eleven brands, and Yong et al. assessed nine commercial samples (13-15). However, these studies focused on in vitro dissolution and mathematical considerations for dissolution profile comparison, without focus on evaluation of other critical quality attributes or assessment of pharmaceutical stability.

The aim of this study was to compare critical quality characteristics, including in vitro dissolution performance, of FURO tablets $(40 \mathrm{mg}$ ) from Argentina and to assess their pharmaceutical equivalence. The stability of the formulations was also considered to evaluate the effect of storage under natural aging conditions for a period of 12 months.

\section{MATERIALS AND METHODS}

\section{Materials}

FURO was obtained from Saporiti (Parafarm, Buenos Aires, Argentina). Distilled water and analytical grade sodium hydroxide $(\mathrm{NaOH})$ and monobasic potassium phosphate (Anedra, Argentina) were used for preparation of assay solutions and dissolution medium.

\section{Commercial Samples}

Eight different FURO (40 mg) tablets were purchased in the Argentine pharmaceutical market, and arbitrarily labeled as I-VIII. Sample III was identified as the reference, and the other formulations consisted in multisource products. Tablets identified as Sample VIII contained $50 \mathrm{mg}$ of a different form of the API (FURO diethylaminoethanol), equivalent to $37 \mathrm{mg}$ of FURO. All experiments were performed within the shelf life of the products. The composition of the evaluated formulations is presented in Table 1.

\section{Equipment}

The employed equipment include an analytical balance (ALC-210.4M, Acculab, Edgewood, NY, USA), a hardness tester (DGM02, Scout Electronics, Villa Ballester, Argentina), a friability tester (FGMO2, Scout Electronics), a disintegration tester (EGMO2, Scout Electronics), a dissolution equipment (DT60, Erweka, Heusenstamm, Germany), a ultraviolet (UV) spectrophotometer (Cary 50 Conc, Varian Instruments, Mulgrave, Australia), and a stability climatic chamber (ICH 830 L, SCT Pharma, Vicente Lopez, Argentina).

Table 1. Excipients Composition

\begin{tabular}{|c|c|c|c|c|c|c|c|c|c|}
\hline \multirow{2}{*}{ Excipient Type } & \multirow{2}{*}{ Excipient } & \multicolumn{8}{|c|}{ Sample } \\
\hline & & 1 & II & $\mathrm{III}^{\mathrm{b}}$ & $\mathrm{IV}^{\mathrm{b}}$ & v & $v i^{b}$ & VII & VIII \\
\hline \multirow{2}{*}{ Filler/Diluent } & Lactose & + & + & + & + & - & + & + & + \\
\hline & Microcrystalline Cellulose & + & - & - & - & - & - & + & - \\
\hline \multirow{6}{*}{ Disintegrant } & Corn starch ${ }^{\mathrm{a}}$ & - & + & + & - & + & + & - & + \\
\hline & Povidone ${ }^{\mathrm{a}}$ & - & + & - & - & + & + & + & + \\
\hline & Crospovidone & - & - & - & + & - & - & - & - \\
\hline & Croscarmellose sodium & - & - & - & - & - & - & + & - \\
\hline & Docusate sodium ${ }^{\mathrm{a}}$ & - & - & - & - & - & - & + & - \\
\hline & Sodium starch glycolate & - & + & - & - & + & - & - & - \\
\hline \multirow{3}{*}{ Glidant } & Sodium lauryl sulphate ${ }^{a}$ & - & - & - & - & - & - & + & - \\
\hline & Colloidal silicon dioxide & + & - & + & + & + & - & + & - \\
\hline & Talc $^{\mathrm{a}}$ & - & - & + & - & + & + & + & - \\
\hline Lubricant & Magnesium stearate & + & + & + & + & + & + & + & + \\
\hline Coloring agent & Ponceau 4R & - & - & - & - & + & - & - & - \\
\hline
\end{tabular}

${ }^{a}$ Multiple functions have been described for this excipient.

${ }^{b}$ The label (or leaflet) informs quantitative composition of excipients.

+ present; - absent 


\section{Quality Control Tests}

The information included in primary and secondary packaging (labels) and patient leaflets was evaluated and compared between samples to confirm compliance with Argentine regulations $(16,17)$.

Ten randomly chosen tablets of each formulation were independently weighed. The results for weight variation analysis were expressed as the mean value and its associated standard deviation (SD).

Argentine Pharmacopeia guidelines were followed to perform friability, hardness, and disintegration tests (16). Ten dosage units from each formulation, previously weighed, were placed into the tester for the determination of friability (i.e., the aptitude of tablets to resist erosion during mechanical processes such as packaging, handling, or shipping). The tablets were reweighed after 100 revolutions ( $4 \mathrm{~min}$ at $25 \mathrm{rpm}$ ), and the result was compared with the value obtained before treatment (16). For hardness determination, 10 tablets of each sample were placed, one at a time, in the hardness tester, and enough force was applied to cause the fracture of the tablet across the diameter. The results were expressed in kilopounds (kip). Disintegration test was performed over six tablets of each sample, using distilled water at $37.0 \pm 2.0^{\circ} \mathrm{C}$ as medium. The specification indicates that all tablets should fully disintegrate after $30 \mathrm{~min}$, unless otherwise stated in the particular monograph (16).

Twenty tablets were weighed and finely ground for the assay test. A portion of the powder containing approximately $40 \mathrm{mg}$ of FURO was exactly weighed and dissolved with $0.05 \mathrm{M} \mathrm{NaOH}$. The prepared solution was filtered and suitably diluted with the same reagent, and the measurements were performed using a calibrated UV spectrophotometer at $271 \mathrm{~nm}$ (18). The standard calibration curve developed for the determination of FURO concentration was $y=60.651 x-0.0034\left(r^{2}=\right.$ 0.9998 ), with a concentration range of $2.0-15.0 \mu \mathrm{g} / \mathrm{mL}$. This assay method was individually applied over 10 tablets of each sample to test the uniformity of dosage units.

For dissolution test, a United States Pharmacopeia (USP) apparatus 2 was used with $900 \mathrm{~mL}$ of phosphate buffer (pH 5.8) at $50 \mathrm{rpm}$ (16). Six samples were evaluated the first step of acceptance criteria (Stage 1, S1). The same conditions were applied for dissolution profiles, where at each sampling time (every $5 \mathrm{~min}$ during the first $15 \mathrm{~min}$ of the test, and every 15 min afterwards until the final sampling point of $60 \mathrm{~min}), 10-\mathrm{mL}$ aliquots were extracted from the vessels and filtered $(0.45-\mu \mathrm{m}$ nylon membrane, Gamafil, Béccar, Argentina). After suitable dilution with the dissolution medium, FURO concentration was measured by spectrophotometric analysis $(276 \mathrm{~nm})$. The amount of FURO dissolved was calculated by the standard calibration curve constructed between concentrations of 2.0 and $15.0 \mu \mathrm{g} / \mathrm{mL}$ ( $\left.y=60.545 x+0.0041, r^{2}=0.9997\right)$. The results were compared with the pharmacopeial specification, which indicates that 'not less than 70\% (Q) of the labeled amount of FURO should dissolve within 45 $\min ^{\prime}(16)$.

Finally, dissolution profiles were also characterized in terms of dissolution efficiency (DE). This modelindependent parameter is defined as the area under the dissolution curve up to a certain time, $t$, expressed as a percentage of the area of the rectangle described by $100 \%$ dissolution in the same time' (19). DE results were statistically compared using analysis of variance (ANOVA), at a level of probability $p$ of $5 \%$. (Infostat, free version, Córdoba, Argentina).

\section{Storage conditions}

The formulations were stored for 12 months in their original packaging under $\mathrm{ICH}$ natural conditions for climatic zone II $\left(25^{\circ} \mathrm{C}, 60 \%\right.$ R.H.) (20). Quality control tests were performed at time zero $\left(T_{0}\right)$ and after storage $\left(T_{12}\right)$.

\section{RESULTS AND DISCUSSION}

Not all tablets containing $40 \mathrm{mg}$ of FURO, available in the Argentine market at the date of this study, are considered equivalent with respect to the information provided about storage conditions (Table 2). It is considered that the correct indication would be to "preserve in wellclosed, inactinic (light-resistant) containers," which should be indicated both in the secondary packaging and in the leaflet (16). Products I, III, V, and VI did not mention the fact of light protection, and none of the samples indicated the requirement of tightly closed packaging. However, all samples referred to conditions of storage temperature, and almost all presented an upper limit of $30^{\circ} \mathrm{C}$ (Table 2).

FURO multisource products exhibited important differences in their price values, and the reference product showed the highest one, even double the most economic available (Table 2). The sample price is a significant factor to consider because in Argentina there is an extensive use of multisource products, and patients make decisions about their interchangeability mostly based on economic considerations.

The results of physical quality control tests are shown in Table 2. Large differences were detected between the weight values of samples, with mean values in the range of $118.4-253.1 \mathrm{mg}$. These variable results could 
Table 2. Results of Quality Control Tests

\begin{tabular}{|c|c|c|c|c|c|c|}
\hline Sample & Price $^{a}$ & Storage Conditions ${ }^{b}$ & $\begin{array}{l}\text { Tablet Weight } \\
(\mathrm{mg}) \text {, mean } \pm \text { SD }\end{array}$ & $\begin{array}{l}\text { Hardness (kip), } \\
\text { mean } \pm \text { SD }\end{array}$ & $\begin{array}{c}\text { Friability } \\
\text { (\% of weight loss) }\end{array}$ & $\begin{array}{c}\text { Disintegration } \\
(\mathbf{s})^{c}\end{array}$ \\
\hline I & 1.28 & $\begin{array}{l}\text { Store in cool and dry room, at a } \\
\text { temperature below } 30^{\circ} \mathrm{C} .\end{array}$ & $200.9 \pm 4.0$ & $6.6 \pm 1.0$ & 0.39 & 20 \\
\hline II & 0.70 & $\begin{array}{c}\text { Store between } 15 \text { and } 30^{\circ} \mathrm{C} \text {, } \\
\text { protected from light. }\end{array}$ & $200.7 \pm 1.8$ & $5.3 \pm 0.3$ & 0.69 & 218 \\
\hline III & 1.83 & Store at a temperature below $30^{\circ} \mathrm{C}$. & $160.6 \pm 1.8$ & $5.2 \pm 0.6$ & 0.79 & 31 \\
\hline IV & 1.34 & $\begin{array}{l}\text { Store in cool and dry room, protected } \\
\text { from light. }\end{array}$ & $253.1 \pm 4.6$ & $5.5 \pm 2.2$ & 0.64 & 64 \\
\hline V & 0.94 & $\begin{array}{l}\text { Store at room temperature, between } \\
\qquad 15 \text { and } 30^{\circ} \mathrm{C} \text {. }\end{array}$ & $213.4 \pm 4.9$ & $8.4 \pm 1.4$ & 0.12 & 108 \\
\hline VI & 0.87 & $\begin{array}{l}\text { Store at room temperature, below } \\
\qquad 30^{\circ} \mathrm{C} .\end{array}$ & $199.6 \pm 1.8$ & $7.4 \pm 0.4$ & 0.51 & 193 \\
\hline VII & 1.04 & $\begin{array}{l}\text { Store in a cool and dry room, } \\
\text { protected from light. }\end{array}$ & $159.9 \pm 1.9$ & $4.8 \pm 0.5$ & 0.27 & 129 \\
\hline VIII & 1.35 & $\begin{array}{c}\text { Store between } 5 \text { and } 30^{\circ} \mathrm{C} \text {, protected } \\
\text { from light. }\end{array}$ & $118.4 \pm 1.7$ & $5.4 \pm 0.3$ & 0.25 & 536 \\
\hline
\end{tabular}

a Price per tablet at the time of analysis (Argentinian Pesos).

${ }^{b}$ Information presented in labels and leaflets.

${ }^{c}$ Maximum time registered for complete disintegration.

be explained based on differences in composition (as shown in Table 1), shape, and size of each pharmaceutical form, with no apparent correlation with fluctuations of the API content or dissolution performance. It can be seen in Table 2 that all evaluated samples complied with the specification for friability test, which states that 'a maximum mean weight loss of not more than $1.0 \%$ is considered acceptable' $(16,21)$. With respect to hardness, the mean values were in the range of 4.8-8.4 kip (Table 2). Although tablet breaking force is a general chapter in several pharmacopeias with no statement of specifications to be fulfilled, the obtained results were considered adequate. The specification for disintegration tests states 'at the end of the time limit specified in the monograph, lift the basket from the fluid and observe the tablets: all of the tablets have disintegrated completely' $(16,21)$. All tested products showed acceptable results, with values in the range of 20-536 s (0.3-8.9 min). Therefore, all samples met the specification for the 30 min disintegration test $(16,21)$.

The World Health Organization (WHO) recommends a strength of $40 \mathrm{mg}$ for FURO oral dosage forms (22). All analyzed samples contain $40 \mathrm{mg}$ of FURO, with the exception of formulation VIII. The latter states $50 \mathrm{mg}$ of FURO diethylaminoethanol, which corresponds to $37 \mathrm{mg}$ of FURO. However, its equivalence in FURO content is not indicated in the label nor the leaflet, which is confusing for patients and health professionals. In the other samples, with exception of product IV, there is a large and visible '40' in the secondary packaging. Moreover, no information about FURO diethylaminoethanol was found in the specialized literature or pharmacopoeias $(16,21)$.

Assay specification indicates that FURO tablets should contain $90.0-110.0 \%$ of the labeled amount $(16,21)$. Assay results (mean \pm SD) at $\mathrm{T}_{0}$ ranged between $91.1 \%$ \pm 2.9 (sample VIII) and $98.5 \% \pm 1.1$ (sample II), and results at $\mathrm{T}_{12}$ were between $94.4 \% \pm 3.0$ (sample VII) and $99.6 \%$ \pm 0.5 (sample V) (Table 3). These results indicate that all samples fulfilled assay specifications at both times of analysis. Statistical evaluation of these values indicated no significant differences detected between assay results at $T_{0}$ and $T_{12}$ for each individual sample. In addition, specifications for the uniformity of dosage unit test indicate that the API content in each single dosage unit should range between $85.0 \%$ and $115.0 \%$ of the labeled amount, and the relative standard deviation should be 
lower than $6.0 \%(16,21)$. All evaluated products fulfilled these requirements at $\mathrm{T}_{0}$ (Table 3 ).

The Argentine Pharmacopoeia specification for in vitro dissolution testing of FURO tablets states that 'not less than $70 \%(\mathrm{Q})$ of the labeled amount of FURO is dissolved in 45 minutes' (16). All formulations complied with the specification for the Stage 1 dissolution test, both at $T_{0}$ and $\mathrm{T}_{12}$, as shown in Table 3. The United States Pharmacopoeia is equivalent but differs in the specification, which indicates that 'not less than $80 \%(Q)$ of the labeled amount of FURO is dissolved in 60 minutes' (21). All samples also met this criterion (data not shown). Figures 1 and 2 show the dissolution profiles of the evaluated products at $T_{0}$ and $T_{12}$, respectively. The dissolution profiles reach the plateau, both at $T_{0}$ and $T_{12}$, at 0-10 min for sample I, 1020 min for samples V and VII, and 30 min for samples II, III, IV, and VI. Sample VIII never reached the plateau and had poor dissolution performance. Statistical comparison of FURO dissolution profiles was performed in terms of DE. Mean DE values were in the range of $61.0-98.6 \%$ at $\mathrm{T}_{0}$, and $61.1-96.1 \%$ at $\mathrm{T}_{12}$, with minimum and maximum values for samples VIII and I, respectively, in both conditions (Table 3). There were not significant differences between DE of the reference formulation (sample III) and samples II, IV, and VI; however, highly significant differences were recorded for samples I, V, VII, and VIII compared to the reference. Highly significant differences were also detected between samples I and VIII, with respect to the rest of the evaluated formulations. The same conclusions were achieved at $T_{0}$ and $T_{12}$. With respect to dissolution stability, only samples IV and VII showed highly significant changes after 12 months of storage under natural conditions. Nevertheless, they still fulfilled dissolution specifications at both times of analysis (Table 3).

Table 3. Results of FURO Dissolution Tests

\begin{tabular}{|c|c|c|c|c|c|}
\hline Sample & $\begin{array}{l}\text { Time of Analysis } \\
\text { (Specifications) }\end{array}$ & $\begin{array}{c}\text { Assay }^{\mathrm{a}} \\
(90.0-110.0 \%)\end{array}$ & $\begin{array}{l}\text { Uniformity of } \\
\text { Dosage Units } \\
\text { (85.0-115.0\%; } \\
\text { RSD }<6.0 \%)\end{array}$ & $\begin{array}{c}\text { Dissolution Test } \\
(\mathrm{S} 1 \text { Stage })^{c} \\
(70 \%(\mathrm{Q}) \text { in } 45 \mathrm{~min})\end{array}$ & $\begin{array}{l}\text { Dissolution } \\
\text { Efficiency }^{\text {a }}\end{array}$ \\
\hline \multirow{2}{*}{ I } & $\mathrm{T}_{0}$ & $95.3 \pm 4.7$ & {$[91.1-100.4] / 4.9$} & [101-109] / 2.5 & $98.6 \pm 2.4$ \\
\hline & $\mathrm{T}_{12}$ & $98.3 \pm 2.8$ & -- & {$[98-105] / 3.2$} & $96.1 \pm 2.9$ \\
\hline \multirow{2}{*}{ II } & $\mathrm{T}_{0}$ & $98.5 \pm 1.1$ & [97.3-99.3] / 1.1 & {$[96-102] / 2.4$} & $83.5 \pm 4.8$ \\
\hline & $\mathrm{T}_{12}$ & $97.8 \pm 1.5$ & -- & [99-102] / 1.9 & $83.5 \pm 3.7$ \\
\hline \multirow{2}{*}{ III } & $\mathrm{T}_{0}$ & $97.2 \pm 2.0$ & [95.2-99.3] / 2.1 & [89-103] / 4.6 & $81.7 \pm 3.4$ \\
\hline & $\mathrm{T}_{12}$ & $98.4 \pm 1.8$ & -- & [100-102] / 1.1 & $83.9 \pm 3.0$ \\
\hline \multirow{2}{*}{ IV } & $\mathrm{T}_{0}$ & $97.6 \pm 2.3$ & {$[95.6-100.1] / 2.4$} & {$[90-99] / 3.0$} & $83.3 \pm 1.1$ \\
\hline & $\mathrm{T}_{12}$ & $95.2 \pm 2.2$ & -- & {$[90-94] / 2.3$} & $80.3 \pm 0.4$ \\
\hline \multirow{2}{*}{$\mathrm{V}$} & $\mathrm{T}_{0}$ & $97.2 \pm 0.2$ & {$[97.0-97.4]$ / 0.2} & {$[91-98] / 2.6$} & $88.2 \pm 2.1$ \\
\hline & $\mathrm{T}_{12}$ & $99.6 \pm 0.5$ & -- & {$[96-100] / 1.8$} & $89.1 \pm 2.9$ \\
\hline \multirow{2}{*}{ VI } & $\mathrm{T}_{0}$ & $96.7 \pm 0.6$ & {$[96.2-97.3] / 0.6$} & {$[97-104] / 2.1$} & $83.7 \pm 2.8$ \\
\hline & $\mathrm{T}_{12}$ & $96.7 \pm 1.2$ & - & {$[96-100] / 2.3$} & $84.4 \pm 3.5$ \\
\hline \multirow{2}{*}{ VII } & $\mathrm{T}_{0}$ & $96.0 \pm 2.5$ & [93.1-97.9] / 2.6 & [88-99] / 4.6 & $88.4 \pm 2.4$ \\
\hline & $\mathrm{T}_{12}$ & $94.4 \pm 3.0$ & -- & [98-99] / 0.8 & $91.9 \pm 1.2$ \\
\hline \multirow{2}{*}{ VIII } & $\mathrm{T}_{0}$ & $91.1 \pm 2.9$ & [87.1-95.2] / 4.1 & {$[80-95]$ / 6.5} & $61.0 \pm 4.2$ \\
\hline & $\mathrm{T}_{12}$ & $96.3 \pm 3.1$ & -- & [86- 95] / 5.4 & $61.1 \pm 3.2$ \\
\hline
\end{tabular}

${ }^{a}$ Results are expressed as mean percentage of labeled amount $\pm S D$.

${ }^{b}$ Results are expressed as [range of percentage of labeled amount] / RSD.

${ }^{c}$ Results are expressed as [range of percentage labeled amount dissolved] / RSD.

FURO, furosemide; $Q$, amount of dissolved FURO, expressed as a percentage of the labeled content of the dosage unit, in the time specified in the dissolution test; S1, first stage of acceptance criteria for dissolution test; T $T_{0}$, time zero; $T_{12}$, time after 12 months storage; RSD: relative standard deviation; -- not applicable. 


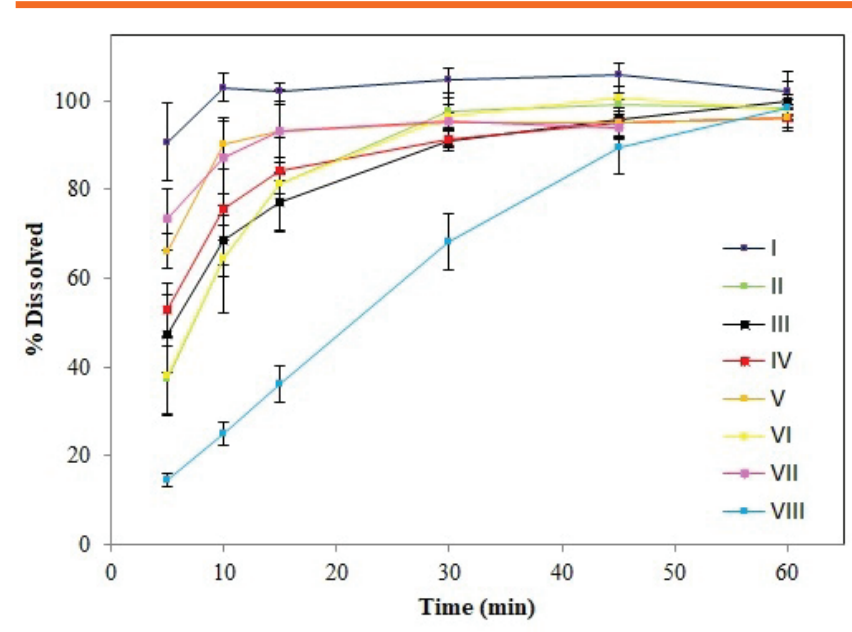

Figure 1. FURO dissolution profiles of samples I-VIII at time zero (To). Data points are mean percentage of labeled amount dissolved at each sampling time with corresponding error bars (standard deviation). FURO, furosemide.

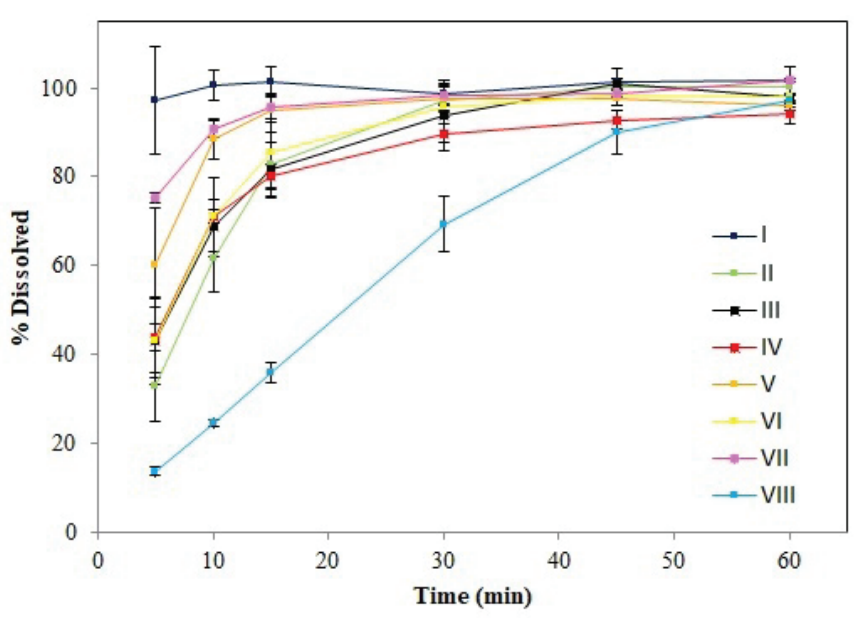

Figure 2. FURO dissolution profiles of samples I-VIII after 12 months of natural aging conditions storage $\left(T_{12}\right)$. Data points are mean percentage of labeled amount dissolved with corresponding error bars (standard deviation). FURO, furosemide.

Table 4. Results of FURO Dissolution Tests with New Batches of Sample VIII

\begin{tabular}{|c|c|c|c|c|c|}
\hline Sample & $\begin{array}{l}\text { Time of Analysis } \\
\text { (Specification) }\end{array}$ & $\begin{array}{c}\text { Assay }^{\mathrm{a}} \\
(90.0-110.0 \%)\end{array}$ & $\begin{array}{l}\text { Uniformity of Dosage Units } \\
\text { (85.0-115.0\%; RSD }<6.0 \%)\end{array}$ & $\begin{array}{l}\text { Dissolution Test, } \\
\text { (S1 Stage })^{c} \\
(70 \%(Q) \text { in } 45 \mathrm{~min})\end{array}$ & $\begin{array}{l}\text { Dissolution } \\
\text { Efficiency }^{\mathrm{a}}\end{array}$ \\
\hline \multirow{2}{*}{ VIIIa } & $\mathrm{T}_{0}$ & $95.1 \pm 0.8$ & [93.9-95.9] / 1.1 & {$[97-104] / 3.3$} & $87.2 \pm 3.8$ \\
\hline & $\mathrm{T}_{12}$ & $93.9 \pm 2.9$ & -- & {$[96-100] / 2.0$} & $83.3 \pm 1.8$ \\
\hline \multirow{2}{*}{ VIIIb } & $\mathrm{T}_{0}$ & $97.7 \pm 2.1$ & [93.0-99.2] / 1.4 & {$[100-105] / 2.4$} & $84.4 \pm 2.3$ \\
\hline & $\mathrm{T}_{12}$ & $95.5 \pm 1.0$ & -- & [95-98] / 1.5 & $80.1 \pm 1.9$ \\
\hline
\end{tabular}

a Results are expressed as mean percentage of labeled amount $\pm S D$.

${ }^{b}$ Results are expressed as [range of percentage of labeled amount] /RSD.

${ }^{c}$ Results are expressed as [range of percentage labeled amount dissolved] / RSD.

FURO, furosemide; $Q$, amount of dissolved FURO, expressed as a percentage of the labeled content of the dosage unit, in the time specified in the dissolution test; S1, first stage of acceptance criteria for dissolution test; $T_{0}$, time zero; $T_{12}$, time after 12 months storage; RSD: relative standard deviation; -- not applicable.

Attending to the significantly lower dissolution performance of formulation VIII, this research further attempted to elucidate the reason for this behavior. Two new batches of the same formulation were evaluated, namely samples VIIla and VIIIb. It is important to highlight that both samples VIIIa and VIIIb presented exactly the same qualitative excipient composition of the original sample VIII (Table 1). Table 4 shows the obtained results for these news batches at $T_{0}$ and $T_{12}$. Both batches fulfilled the specifications for assay, uniformity of dosage units, and dissolution test at both times of analysis; however, the dissolution profiles of VIIla and VIIIb differed from VIII, with a considerably better dissolution performance compared to the original sample VIII (Fig. 3). Highly significant differences were recorded between
DE results of sample VIII with respect to VIIIa and VIIIb, both at $\mathrm{T}_{0}(61.0 \%$ versus $87.2 \%$ and $84.4 \%)$ and $\mathrm{T}_{12}(61.1 \%$ versus $83.3 \%$ and $80.1 \%)$. Additionally, samples VIIla and VIIlb showed significant differences in DE results after 12 months of storage compared to $T_{0}$. Considering that the three samples (VIII, VIIIa and VIIIb) presented exactly the same excipient composition and that the poor dissolution performance of sample VIII was not repeated in the other samples of the same product, it can be concluded that this behavior was due to a particular batch problem. Although the dissolution performance of the new batches was statistically affected by aging, they still fulfilled pharmacopoeial specifications. 


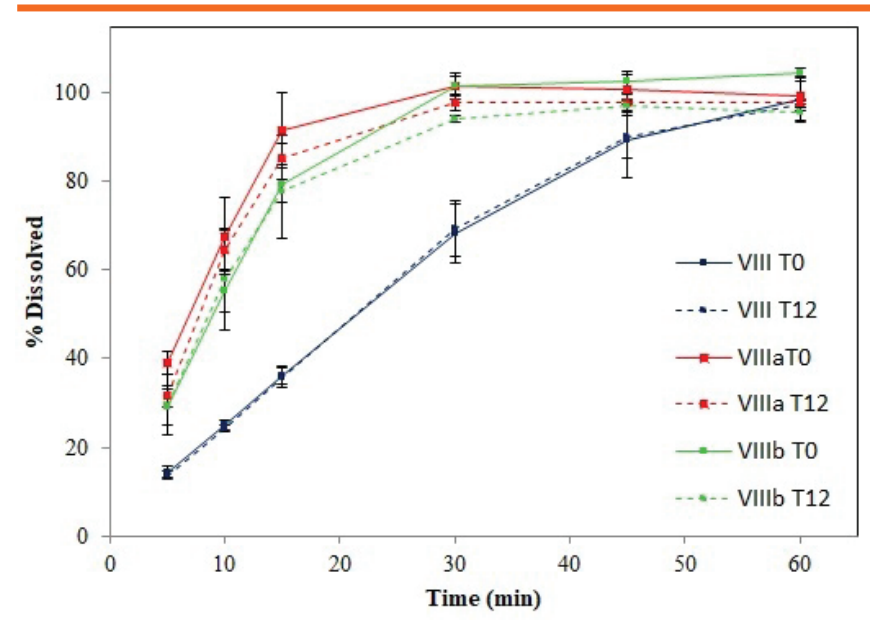

Figure 3. FURO dissolution profiles of samples VIII, VIIIa, and VIIIb at time zero $\left(T_{0}\right)$ and after storage $\left(T_{12}\right)$. Data points are mean percentage of labeled amount dissolved with corresponding error bars (standard deviation). FURO, furosemide.

\section{CONCLUSION}

The evaluated samples were considered pharmaceutical equivalents under the experimental conditions employed. Despite some statistical differences detected in the dissolution profiles, all evaluated products fulfilled pharmacopeial specifications and passed the quality control tests after 12 months of storage. One of the evaluated formulations showed a very low dissolution performance, but it was later confirmed that it corresponded to a particular batch problem. Our results demonstrate that FURO products available in the local market are stable pharmaceutical equivalents.

\section{FUNDING}

We thank Universidad Nacional del Sur for the financial support (Project code: PGI 24/ZB70).

\section{CONFLICT OF INTEREST}

The authors declare no conflict of interest related to this article.

\section{REFERENCES}

1. ANMAT 3185 Regulation: Approval of the technical recommendations contained in the document "Schedule for requirements of equivalence studies between medicines of significant health risk"; Administración Nacional de Medicamentos, Alimentos y Tecnología Médica (ANMAT): Buenos Aires, Argentina, 1999. DOI: 10.11606/issn.2316-9044. v10i3p115-151.

2. WHO Expert Committee on Specifications for Pharmaceutical Preparations. Multisource (generic) pharmaceutical products: guidelines on registration requirements to establish interchangeability; WHO Technical Report Series, No. 1003, Annex 6; World Health Organization: Geneva, Switzerland,
2017; pp 181-236. DOI: 10.1002/jps.2600620248.

3. Murthy, K. S.; Ghebre-Sellassie, I. Current perspectives on the dissolution stability of solid oral dosage forms. J. Pharm. Sci. 1993, 82, 113-126. DOI: 10.1002/jps.2600820202.

4. Sweetman, S. Martindale: The complete drug reference. Pharmaceutical Press, Thomson/MICROMEDEX: London, UK/ Greenwood Village, USA, 2009.

5. Murtaza, G.; Khan, S. A.; Naham-ul-Haq, M.; Hussain, I. Comparative evaluation of various solubility enhancement strategies for furosemide. Pak. J. Pharm. Sci. 2014, 27, 963-973.

6. WHO Expert Committee on Specifications for Pharmaceutical Preparations. Proposal to waive in vivo bioequivalence requirements for WHO Model List of Essential Medicines immediate-release solid oral dosage forms; WHO Technical Report Series, No. 937, Annex 8, World Health Organization: Geneva, Switzerland, 2006; pp 391-437. DOI: 10.1002/ jps.2600620248.

7. Kasim, N. A.; Whitehouse, M.; Ramachandran, C.; Bermejo, M.; Lennernas, H.; Hussain, A. S.; Junginger, H. E.; Stavchansky, S. A.; Midha, K. K.; Shah, V. P.; Amidon, G. L. Molecular properties of WHO essential drugs and provisional biopharmaceutical classification. Mol. Pharm. 2004, 1, 85-96. DOI: 10.1021/ mp034006h.

8. Lindenberg, M.; Kopp, S.; Dressman, J. B. Classification of orally administered drugs on the World Health Organization model list of essential medicines according to the biopharmaceutics classification system. Eur. J. Pham. Biopharm. 2004, 58, 265278. DOI: 10.1016/j.ejpb.2004.03.001.

9. Granero, G. E.; Longhi, M. R.; Mora, M. J.; Junginger, H. E.; Midha, K. K.; Shah, V. P.; Stavchansky, S. A.; Dressman, J. B.; Barends, D. M. Biowaiver monograph for immediate release solid oral dosage forms: Furosemide. J. Pharm. Sci. 2010, 99, 2544-2556. DOI: 10.1002/jps.22030.

10. ANMAT 4788 Regulation: Incorporate the requirements for carrying out the Bioavailabiliy/Bioequivalence studies, established by ANMAT 3185/99 Regulation, to the active pharmaceutical ingredients listed in Annex l; Administración Nacional de Medicamentos, Alimentos y Tecnología Médica (ANMAT): Buenos Aires, Argentina, 2012. DOI: 10.11606/ issn.2316-9044.v10i3p115-151.

11. Qureshi, S. A.; McGilveray, I. J. Assessment of pharmaceutical quality of furosemide tablets from multinational markets. Drug Dev. Ind. Pharm. 1998, 24, 995-1005. DOI: 10.3109/03639049809089943.

12. Akbuga, J.; Gürsoy, A. Studies on Furosemide Tablets I. Dissolution of commercial products and different formulations. Drug Dev. Ind. Pharm. 1987, 13, 2199-2208. DOI: 10.3109/03639048709020580.

13. Maggio, R. M.; Castellano, P. M.; Kaufman, T. S. A new principal component analysis-based approach for testing "similarity" of drug dissolution profiles. Eur. J. Pharm. Sci. 2008, 34, 66-77. DOI: 10.1016/j.ejps.2008.02.009. 
14. Ruiz, M. E.; Gregorini, A.; Talevi, A.; Volonté, M. G. Dissolution studies of generic medications: new evidence of deviations from the Transitivity principle. Dissolution Technol. 2012, 19, 13-24. DOI: 10.14227/DT190112P13.

15. Yong, K. H.; Simionato, L. D.; Calvo, R. G.; Mattei, M. B.; Segall, A. I. Comparison of dissolution profiles of furosemide tablets available in the Argentinian Market. J. App. Sol. Chem. Model. 2014, 3, 186-193. DOI: 10.6000/1929-5030.2014.03.04.1

16. Argentine Pharmacopeia, 7th Ed; Administración Nacional de Medicamentos, Alimentos y Tecnología Médica (ANMAT): Buenos Aires, Argentina, 2013.

17. ANMAT 5904 Regulation: Definitions and general guidelines on how the information should be included in the leaflets of pharmaceutical products whose condition of sale is under prescription; Administración Nacional de Medicamentos, Alimentos y Tecnología Médica (ANMAT): Buenos Aires, Argentina, 1996. DOI: 10.11606/issn.2316-9044.v10i3p115-151.
18. Japanese Pharmacopoeia, 17th ed.; Ministry of Health, Labour, and Welfare: Tokyo, Japan, 2016.

19. Khan, K. A. The concept of dissolution efficiency. J. Pharm. Pharmacol. 1975, 27, 48-49. DOI: 10.1111/j.2042-7158.1975. tb09378.x.

20. International Council for Harmonisation of Technical Requirements for Pharmaceuticals for Human Use (ICH). Stability Testing of New Drugs and Substances and Products. In: ICH Harmonised Tripartite Guidelines, ICH Q1A (R2); ICH Harmonized Tripartite Guideline, Geneva, Switzerland, 2003. DOI: $10.1007 /$ springerreference_83218.

21. The United States Pharmacopeia and National Formulary USP 41-NF 36; The United States Pharmacopeial Convention, Inc., Rockville, MD, 2018. DOI: 10.4135/9781412963855.n1200.

22. WHO Model List of Essential Medicines, 20th ed. World Health Organization: Geneva, Switzerland, 2017. 